\title{
Miscibility of poly(thiophene-3-acetic acid) and poly(ethylene oxide)
}

\author{
K.H. Hsieh ${ }^{\mathrm{a}, *}$, K.S. Ho ${ }^{\mathrm{b}}$, Y.Z. Wang ${ }^{\mathrm{c}}$, S.D. Ko ${ }^{\mathrm{a}}$, S.C. Fu ${ }^{\mathrm{a}}$ \\ a Department of Chemical Engineering, National Taiwan University, Taipei 106, Taiwan \\ ${ }^{\mathrm{b}}$ Department of Chemical Engineering, National Kaohsiung Institute of Technology, Kaohsiung 807, Taiwan \\ ${ }^{\mathrm{c}}$ Department of Chemical Engineering, National Yunlin University of Science and Technology, Yun-Lin 640, Taiwan
}

Received 28 April 2000; received in revised form 30 November 2000; accepted 30 November 2000

\begin{abstract}
Poly(thiophene-3-acetic acid) (PTAA), prepared from polymerization of ethyl-thiophene-3-acetate followed by hydrolysis, was blended with poly(ethylene oxide) (PEO). The $1.5 \%$ aqueous ammonia solution was used as a solvent in the blending process and a base for the neutralization of acetic acid side chain of PTAA, which also results in the dissolution of PTAA in the solvent. Thermal analysis by DSC thermograms of PTAA/PEO blends shows that the melting points of PTAA/PEO blends are slightly lower than that of the neat PEO when re-crystallized from molten state. This specific interaction of the blends was analyzed by FT-IR spectra and characterized by shifting of characteristic absorption peaks of $-\mathrm{COO}^{-}$and $-\mathrm{NH}_{4}{ }^{+}$. This specific interaction was due to the combination effect of the ionic and $\mathrm{H}-$ bonding. The X-ray diffraction patterns show no change of both PEO and PTAA lattice after blending. The degradation temperatures of the blends, as measured by the thermogravimetric analysis (TGA), are higher than the pure PTAA. According to the pictures of PTAA/PEO film taken from the optical microscopy $(\mathrm{OM})$, the melting point $\left(T_{\mathrm{m}}\right)$, phase equilibrium curve, and degradation temperature $\left(T_{\mathrm{d}}\right)$ of blend samples can be roughly measured. Combined the $T_{\mathrm{m}}$ obtained from the DSC data and the cloud point defined as the temperature when a sharp increase of the exposure time of the OM camera, a phase diagram (PD) can be constructed. The conductivity of PTAA in PTAA/PEO is slightly affected by the existence of this specific interaction and different compositions with different morphology. (C) 2001 Elsevier Science B.V. All rights reserved.
\end{abstract}

Keywords: Poly(thiophene-3-acetic acid); Polyblends; Poly(ethylene oxide); Conducting polymer

\section{Introduction}

Polymers can be made conducting through the creation of the continuous conjugation along the main chains followed by the suitable doping which can then create the conducting charges. Based on this idea, a lot of conducting polymers were synthesized and their conductivity can even reach the level of metallic compound upon doping. However, the following problems happen when there are so many conjugations along the main chains. First, the backbones become so rigid that no solvents can be found, especially when doping to create the charges along the backbones resulting in a polymers with very high solubility parameter [1] but no solvent can be found. Second, the degradation comes before melting which resulting in the lack of melting point, and then making the polymers impossible for processing. If these two problems can be solved, the conducting

\footnotetext{
* Corresponding author. Tel.: +886-2-2362-7688; fax: +886-2-2362-7688.

E-mail address: khhsieh@ccms.ntu.edu.tw (K.H. Hsieh).
}

polymers can be processed in the molding machines or made into film with the help of solvents.

One of the effective ways to improve the processability of the rigid conducting polymers is attaching flexible or soluble side chains to the backbones. Based on the idea, polythiophene (PT) which is another kind of conducting polymers has the similar problem of insolubility was made soluble in organic solvents by covalent bonded long alkyl side chains to the backbone [2]. With the alkylation at the side chain the poly(alkyl thiophene) can even be processed like regular thermoplastic polymers [3,4]. Heeger et al. [5-9] attached the alkyl side groups to the thiophene backbone to weaken the strong interaction between the main chains molecules without a remarkable loss of the conductivity. The similar situation happens to polyaniline which becomes soluble and can be blended with other matrix polymers after doping with $n$-dodecylbenzene sulfonic acid which has a long alkyl side chain [10-13]. Although conducting polymers can be made soluble and processible, they cannot totally replace other polymers which have been widely used in lots of fields because of their roles can only be played like additives which are used to improve the electric properties of the 
matrix polymers but not cause any change of the original properties of the matrix polymers. For example, the conductivity of matrix polymers can be improved when mixed with the conducting polymers through the suitable blendings. Consequently, some commercially available polymers were used to mixed with PT or poly(3-alkyl thiophenes) (PAT) in solvents or by melt-mixing [14-21]. However, these polyblends are usually immiscible due to the tiny change of entropy after mixing and lack of strong specific interaction between the non-polar side chains of PAT and matrix polymers. Therefore, these studies cannot give us a thermodynamically stable polyblend sample to construct a real phase diagram (PD) which can provide the miscibility and procession window for a real application. Our approach is to attach a polar group instead of non-polar alkyl group to the side chains of PT, which would be more easily form a specific interaction with the matrix polymers and create a thermodynamically miscible system. Then, we can measure the so-called phase separation temperatures and construct a PD which can also provide us the suitable processing conditions to obtain the morphology having higher conductivity with the less addition of conducting polymers.

\section{Experimental}

\subsection{Materials}

The materials used in the preparation and testing are list in Table 1.

\subsection{Preparation of poly(thiophene-3-acetate)}

Ethylenethiophene-3-acetate was polymerized through oxidization by dried ferric chloride with a molar ratio of 4 to 1 in chloroform under the purged nitrogen gas for $6 \mathrm{~h}$ at $50^{\circ} \mathrm{C}$ [22]. The reaction mixture was cooled down to room temperature and kept over night after which the black filter cake was isolated and dissolved in THF solvent. When most of the THF was removed, the poly(ethylenethiophene-3acetate) (PTA) was obtained. To synthesize the poly(thiophene-3-acetic acid) (PTAA), PTA was hydrolyzed in the sodium hydroxide aqueous solution for $40 \mathrm{~h}$ at $70^{\circ} \mathrm{C}$, followed by acidification in concentrated hydrochloric acid.

Table 1

List of materials

\begin{tabular}{lll}
\hline Materials & Composition & Source \\
\hline Ethyl thiophene-3-acetate & $\mathrm{C}_{8} \mathrm{H}_{10} \mathrm{O}_{2} \mathrm{~S}$ & Aldrich \\
Ferric chloride & $\mathrm{FeCl}_{3}$ & Janssen \\
Chloroform & $\mathrm{CHCl}_{3}$ & Fisher \\
Tetrahydrofuran & $\mathrm{C}_{4} \mathrm{H}_{8} \mathrm{O}$ & Fisher \\
Sodium hydroxide & $\mathrm{NaOH}$ & Nacalai \\
Hydrochloric acid & $\mathrm{HCl}$ & Wako \\
Ammonium water & $\mathrm{NH}_{4} \mathrm{OH}$ & Wako \\
Iodine & $\mathrm{I}_{2}$ & Hagashi \\
\hline
\end{tabular}

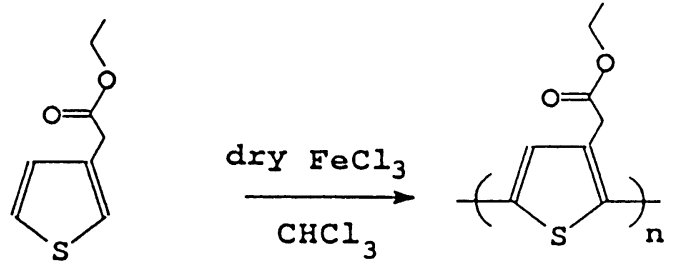

Ethylenethiophene-3-acetate

PTA
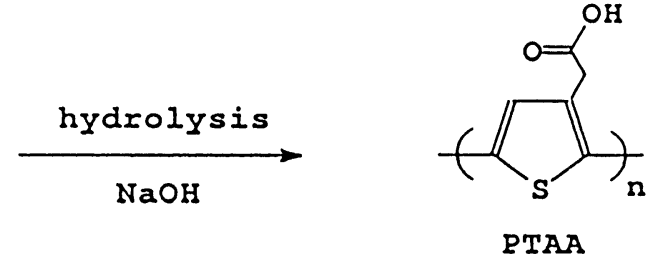

Scheme 1. Synthesis of poly(thiophene-3-acetic acid).

The PTAA was isolated by filtration and washed several times by deioned water before drying in a vacuum oven at $60{ }^{\circ} \mathrm{C}$ for 2 days. The yield is about $56 \%$. The reaction is shown as Scheme 1.

\subsection{Characterization}

PTA, PTAA, and PTAA/PEO were mixed with dry $\mathrm{KBr}$ powders, pressed into tablet and analyzed by FT-IR (BioRad FTS-40). The resolution $2 \mathrm{~cm}^{-1}$ and scanning time 16 were used for the analysis.

\subsection{Preparation of PTAA/PEO blends}

PTAA $(0.1 \%)$ and poly(ethylene oxide) (PEO) (1\%) in $1.5 \%$ aqueous ammonia solution were separately prepared in a $100 \mathrm{ml}$ volumetric flask, and then followed by stirring in room temperature for $24 \mathrm{~h}$.

Different compositions of PTAA/PEO blend were prepared by pouring the equivalent volume of each polymer solution into a flask and stirred for another $24 \mathrm{~h}$ before casting on a glass plate. The solutions were cast at room temperature for $24 \mathrm{~h}$, followed by heating in a oven at $45^{\circ} \mathrm{C}$ under vacuum for 2 days until there is no change of sample weight.

\subsection{Differential scanning calorimetry (DSC)}

The melting points of pure PEO and PTAA/PEO (PEO over $50 \%$ ) blends were measured by a Perkin-Elmer DSC 7 at a scanning rate of $10^{\circ} \mathrm{C} / \mathrm{min}$. The sample was kept at $100^{\circ} \mathrm{C}$ for $10 \mathrm{~min}$ to ensure the complete melting of PEO crystals before each measurement.

\subsection{X-ray diffraction}

X-ray diffraction patterns of crystallizable samples were measured by powder method with a Mac Science X-ray 
diffractometer scanned from $5^{\circ}$ to $40^{\circ}$ at $0.02^{\circ} / \mathrm{s}$ with a power of 40 and $30 \mathrm{~mA}$.

\subsection{Thermogravimetric analysis (TGA)}

The degradation temperature of sample was measured by a Perkin-Elmer TGA 7 with a heating rate of $10^{\circ} \mathrm{C} / \mathrm{min}$ at the temperature ranged from 50 to $450^{\circ} \mathrm{C}$ under a nitrogen atmosphere.

\subsection{Optical microscopy}

The phase separation temperature of the blended sample was determined at the temperature when a sudden increase of the exposure time of the camera system in the optical microscopy $(\mathrm{OM})$. The $\mathrm{OM}$ was conducted at a heating rate of $5^{\circ} \mathrm{C} / \mathrm{min}$ ranged from room temperature to $200^{\circ} \mathrm{C}$. The OM pictures were taken with the magnification of 400 in a bright field mode.

\subsection{Doping}

The PTAA and PTAA/PEO blends after staying at $140^{\circ} \mathrm{C}$ for $10 \mathrm{~min}$ were doped with iodine vapor under vacuum. The excess iodine in the sample was evaporated under vacuum until the sample weight decreased to a constant value (about $5 \mathrm{~h})$. Therefore, the sample with higher PTAA content had higher weight of the sample after iodine doping and vacuum.

\subsection{Conductivity measurement}

The conductivity of pure PTAA and PTAA/PEO blends were measured by a four-point probe meter (Keighley).

\section{Results and discussion}

Characterization of PTAA and its precursor PTA were conducted by FT-IR analysis. The (a) curve in Fig. 1 shows

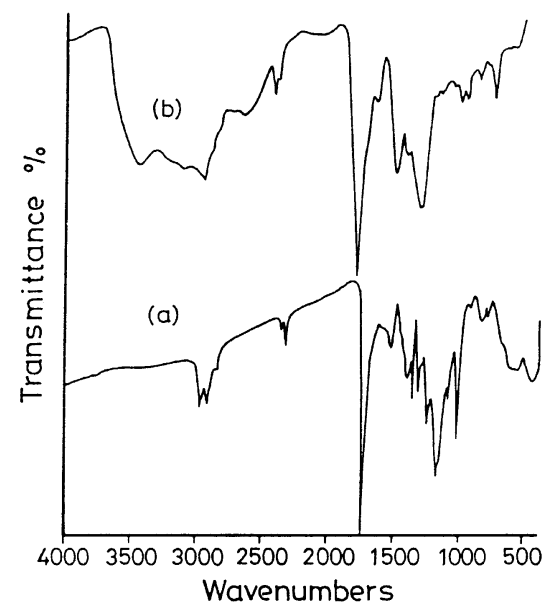

Fig. 1. FT-IR spectra of: (a) PTA; (b) PTAA.

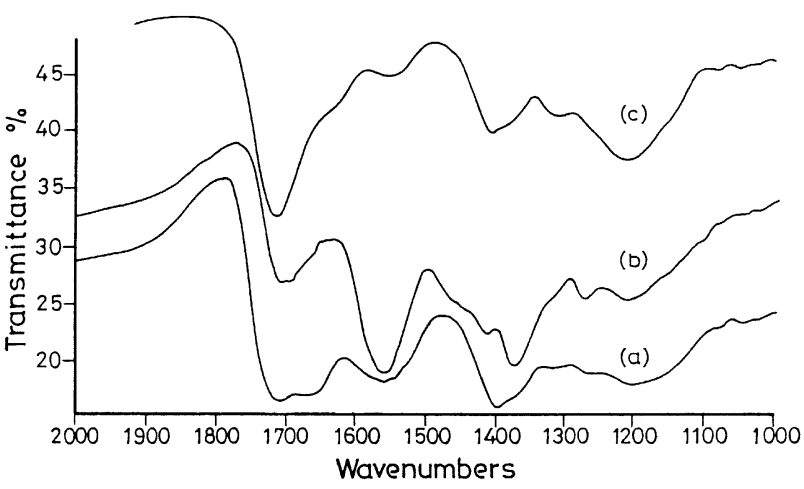

Fig. 2. FT-IR spectra of aqueous ammonia solution cast: (a) PTAA $\left(300^{\circ} \mathrm{C}\right)$; (b) PTAA; (c) pure PTAA.

the spectrum of the PTA, in which the absorption peak at $1710 \mathrm{~cm}^{-1}$ [22] is related to the carbonyl group of acetate and the (b) curve is the spectrum of the PTAA obtained from the hydrolysis of PTA. After hydrolysis the absorption peak of carbonyl group shifts to $1739 \mathrm{~cm}^{-1}[23,24]$ which is corresponding to the absorption of free carboxylic groups of PTAA. The broad absorption between $3000-3500 \mathrm{~cm}^{-1}$ [25] of PTAA is caused by the appearance of - $\mathrm{OH}$ group resulting from the hydrolysis of PTA. Comparing the spectrum in Fig. 1, we can also find the stretching modes of saturated hydrocarbon groups $-\mathrm{CH}_{2} \mathrm{CH}_{3}$ around $3000 \mathrm{~cm}^{-1}$ are not significantly shifted in the hydrolysis process.

Fig. 2 illustrates the FT-IR spectra of neat PTAA in the (c) curve and cast PTAA with aqueous ammonia solution. A large and strong absorption peak around $1560 \mathrm{~cm}^{-1}$ appeared in the (b) curve of Fig. 2 is attributed to the formation of $-\mathrm{COO}^{-}$group by the neutralization of acetic acid with ammonia in aqueous solution [23]. It also causes an extra absorption peak at $1370 \mathrm{~cm}^{-1}$ due to the formation of counterion $\mathrm{NH}_{4}^{+}$group [23]. The ammonia group can be removed by heating the sample at $300^{\circ} \mathrm{C}$ for $1 \mathrm{~h}$, as shown by the disappearance of the peaks in the (a) spectrum of Fig. 2. However, the high temperature treatment to the sample might also cause the degradation of PTAA by the evolution of $\mathrm{CO}_{2}$ from acetic acid group. Therefore, the growth of a peak at $1658 \mathrm{~cm}^{-1}$ in the (a) spectrum was observed.

\subsection{Differential scanning calorimetry}

The miscibility of PTAA/PEO blends system was characterized by the $T_{\mathrm{m}}$ (melting point) depression of PEO, which was measured from DSC thermograms. PEO is able to crystallize, as its composition in PTAA/PEO blends is higher than $50 \%$ as seen in Fig. 3. It shows the $T_{\mathrm{m}}$ 's of pure PEO and its blends with 90, 70, 50\% PEO in compositions. In order to ensure the complete melting of the PEO crystals, all samples were heated at $100^{\circ} \mathrm{C}$ for $10 \mathrm{~min}$. As shown in the DSC thermograms, the $T_{\mathrm{m}}$ 's of PEO decreases due to the interaction with the PTAA of the blends. For those blends with low PEO contents, they are not able to re-crystallize 


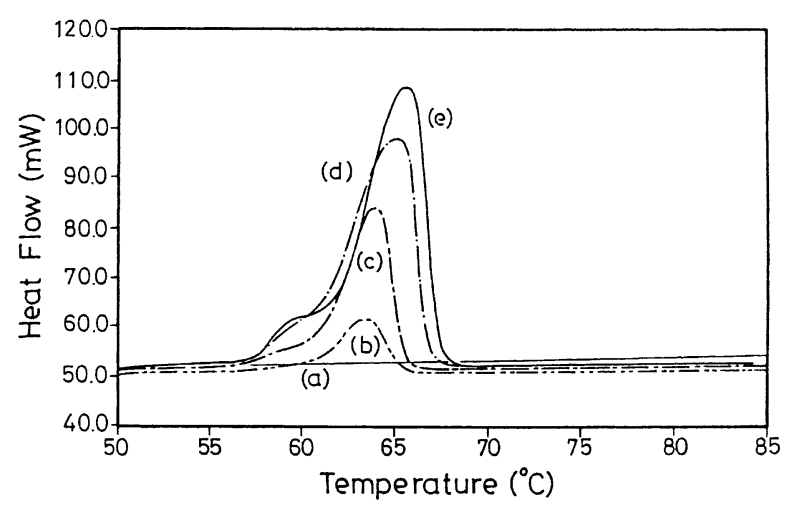

Fig. 3. DSC thermograms of PTAA/PEO: (a) 70/30; (b) 50/50; (c) 30/70; (d) $10 / 90$; (e) $0 / 100$.

when quenched from the molten state at $100^{\circ} \mathrm{C}$. The normalized heats of fusion (based on per gram of PEO) for the blends are listed in Table 2, and illustrate a decreasing trend with the $T_{\mathrm{m}}$ depression of the PEO. It also demonstrates that the increasing interaction from PTAA interferes the crystallization of the blends and makes a thinner lamella of PEO crystallite.

\subsection{Infrared spectroscopy}

To characterize the interaction between the PTAA and PEO molecules, the PTAA/PEO blends with various compositions (0/100, 10/90, 30/70, 50/50, 70/30, 90/10, 100/0) were measured with infrared spectroscopy. The IR spectra of PTAA/PEO blends as shown in Fig. 4 illustrates that the peak of free carboxylic acid group in PTAA, which is assigned for the absorption at $1739 \mathrm{~cm}^{-1}$, is remained at the same wavenumber after mixing with PEO. It means that the acetic acid groups do not associate with PEO through $\mathrm{H}-$ bonding but keep at the H-bonding free state. However, another absorption peak at $1550-1600 \mathrm{~cm}^{-1}$, resulting from the $-\mathrm{COO}^{-}$, varies with PEO contents and slightly shifts to higher wave number with the increase of the PEO content. It indicates that the interactions with PEO molecules are something to do with the ammonium ions since $-\mathrm{COO}^{-}$ is firmly attracted by ammonium ions after neutralization. The interaction, which has been proved to exist by the $T_{\mathrm{m}}$

Table 2

Melting points $\left(T_{\mathrm{m}}\right)$ and normalized heat of fusion $(\Delta H)$ of PTAA/PEO blends

\begin{tabular}{lll}
\hline PTAA/PEO & $T_{\mathrm{m}}\left({ }^{\circ} \mathrm{C}\right)$ & $\Delta H(\mathrm{~J} / \mathrm{g})$ \\
\hline $100 / 0$ & $\mathrm{ND}^{\mathrm{a}}$ & $\mathrm{ND}$ \\
$90 / 10$ & $\mathrm{ND}$ & $\mathrm{ND}$ \\
$70 / 30$ & $\mathrm{ND}$ & $\mathrm{ND}$ \\
$50 / 50$ & 63.3 & 57.8 \\
$30 / 70$ & 63.8 & 124.9 \\
$10 / 90$ & 65.1 & 168.8 \\
$0 / 100$ & 65.6 & 176.7
\end{tabular}

${ }^{\mathrm{a}} \mathrm{ND}$ : not detectable.

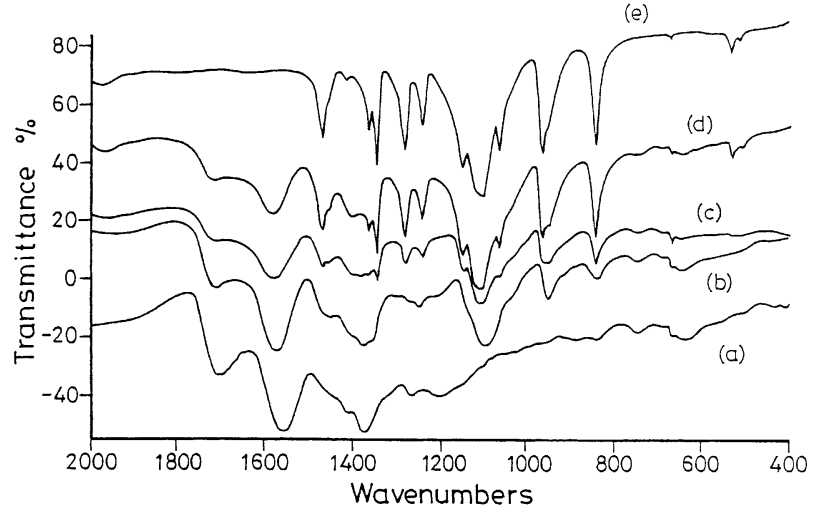

Fig. 4. FT-IR spectra of PTAA/PEO: (a) 0/100; (b) 70/30; (c) 50/50; (d) $30 / 70$; (e) $0 / 100$.

depression, may come from the negative carboxylic and positive ammonium ions. In other words, only after ionization can the PTAA create a $-\mathrm{COO}^{-}$group and interact with PEO. The ammonium ion play an important role in the blends since it is capable of forming both ionic and $\mathrm{H}$ bonding with PTAA and PEO molecules, respectively. The evidence of the formation of H-bonding is shown by the splitting of the absorption peak at $1370 \mathrm{~cm}^{-1}$ in higher PTAA composition due to the more carboxylic groups formed, which can then interact with PEO and result in the depression of PEO in PTAA/PEO blends. It can also hinder the re-crystallization of most of PEO molecules as seen from Fig. 3 and Table 2, which shows no $T_{\mathrm{m}}$ for the blends when the PEO content is below $50 \%$. In other words, the ammonium ions behave like bridges which link both types molecules together through ionic and H-bonding as shown in Scheme 2.

\subsection{X-ray diffraction patterns}

The crystallized samples were investigated by X-ray diffraction to check any change of the lattice of PTAA/ PEO blends upon blending. Fig. 5(a) and (b) show the same the X-ray diffraction patterns of PTAA before and after casting from $1.5 \%$ aqueous ammonia solution. When we calculated the equivalent amount of ammonium hydroxide in the $1.5 \%$ aqueous ammonia solution, only about $5 \%$ equivalents of acetic acid can be neutralized by aqueous ammonia solution. The interaction happening through these $5 \%$ is strong enough to alter the crystalline structure of PTAA or PEO since the neutralized acetic acid may also induce the self-repulsion effect between the neighboring acetic acid groups and decease the opportunity for the approaching of the PEO molecules. That is why the $\mathrm{X}$ ray diffraction pattern of 50/50 (Fig. 5(c)) has the characteristic patterns of both the pure PTAA (Fig. 5(b)) and PEO (Fig. 5(d)). In other words the PTAA molecules in the blends behave like the impurities which only cause the depression of $T_{\mathrm{m}}$ 's but not change both own PEO crystalline structures. However, this small interaction is large enough to improve 


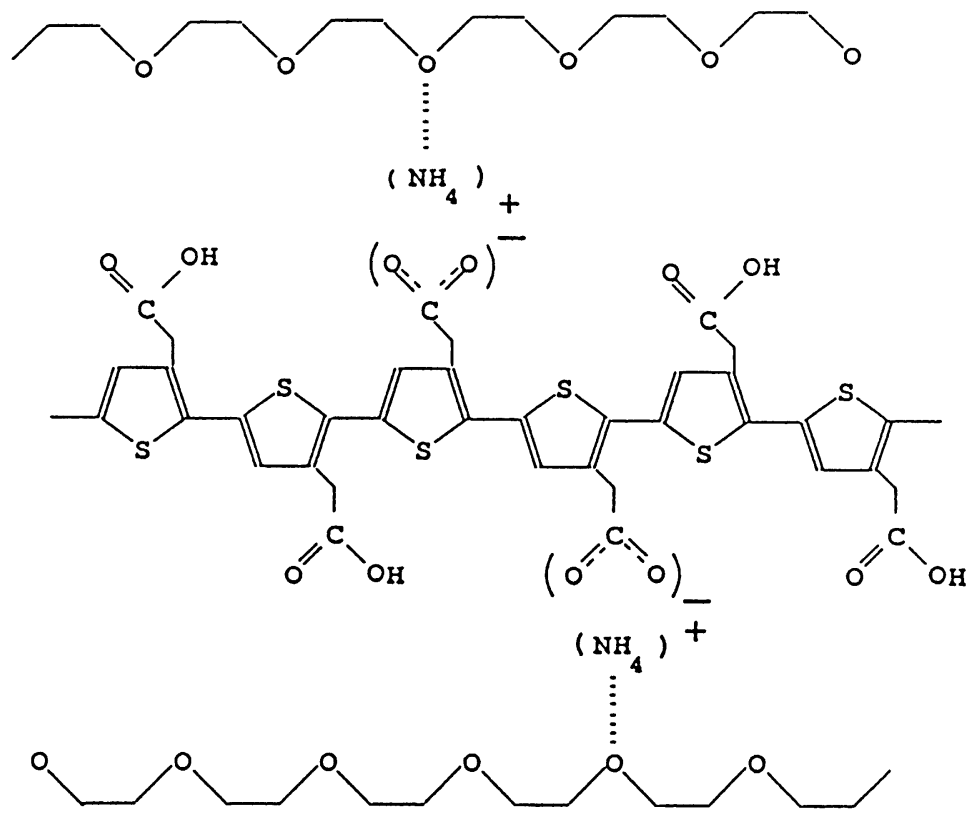

Scheme 2. Diagram of specific interaction between PTAA and PEO.

the miscibility between PTAA and PEO. Of course, the interaction may increase if we increase the degree of neutralization of PTAA by putting higher concentration of aqueous ammonia solution. However, this may also cause the change of the conformation of PTAA molecules by forming a polyelectrolyte-like polymer and induce more intramolecular interferences which would then complicate the miscibility of the PTAA/PEO blends.

\subsection{Thermogravimetric analysis}

The thermal degradation property of PTAA/PEO blends was investigated by thermogravimetric analysis (TGA). As seen from Fig. 6(a), the cast PTAA starts to degrade at

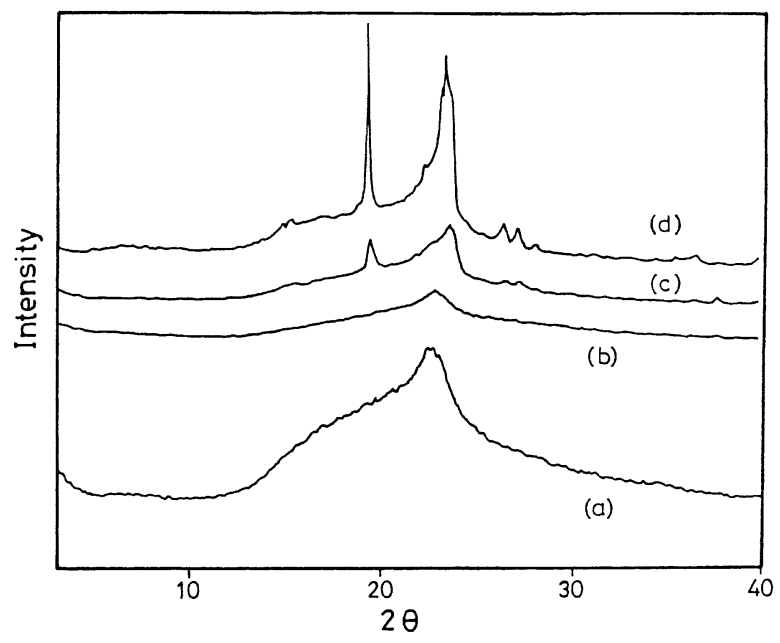

Fig. 5. X-ray diffraction patterns: (a) pure PTAA; (b) cast PTAA; (c) PTAA/PEO 50/50; (d) cast PEO. $200^{\circ} \mathrm{C}$. The loss of $\mathrm{CO}_{2}$ of acetic acid group can possibly occur above $300^{\circ} \mathrm{C}$ where a sharp weight loss was observed. The weight losses very slowly and shows a highly thermal resistance due to the possible carbonization of PTAA above this temperature. Unlike PTAA, the pure PEO demonstrates a sharp weight loss at temperature above $410^{\circ} \mathrm{C}$ as shown in Fig. 6(c). However, the PTAA/PEO blend of 50/50 ratio (Fig. 6(b)) starts to lose weight at a higher temperature than the pure PTAA and remains a higher char yield than the pure PEO.

\subsection{Optical microscopy}

From the above discussions, there is an interaction presented in the PTAA/PEO blends when they are prepared from $1.5 \%$ aqueous ammonia solution. Consequently, the

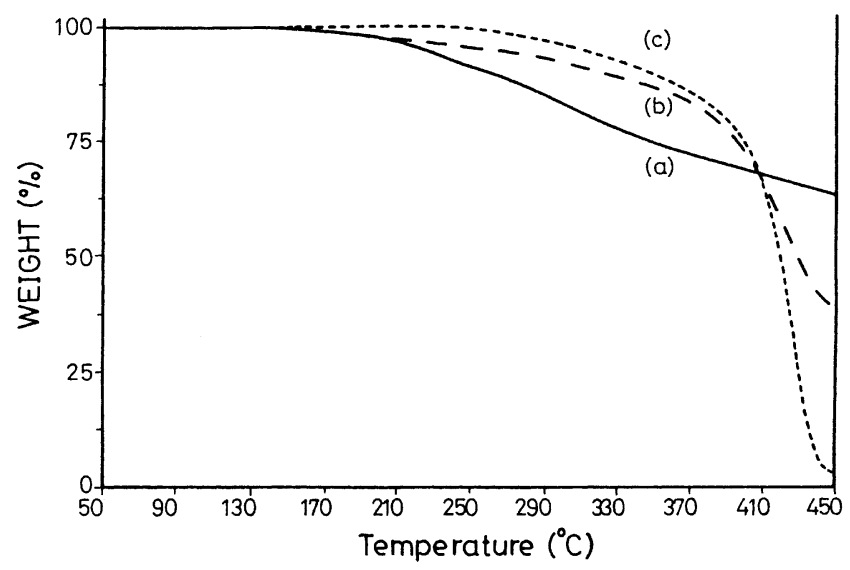

Fig. 6. TGA thermograms of: (a) cast PTAA; (b) PTAA/PEO 50/50; (c) cast PEO. 
cloud point can be measured by a optical microscopy (OM) on a hot stage. Because of the nature orange color of the PTAA, we can easily distinguish the PTAA from the PEOrich domains by the different color. The PTAA-rich phase shows a brown color but the PEO-rich phase owns a light yellow color, which provides a strong contrast around the phase boundaries. Fig. 7(a) is the OM photograph of the blend for the PTAA/PEO of 30/70 ratio, which shows a shining crystalline domain of the PEO-rich region at room temperature $\left(27^{\circ} \mathrm{C}\right)$ and a yellow color observed due to the

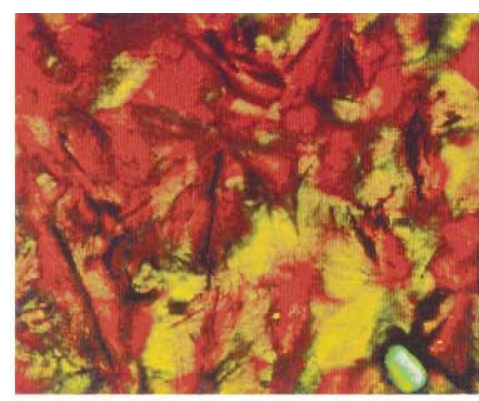

(a)

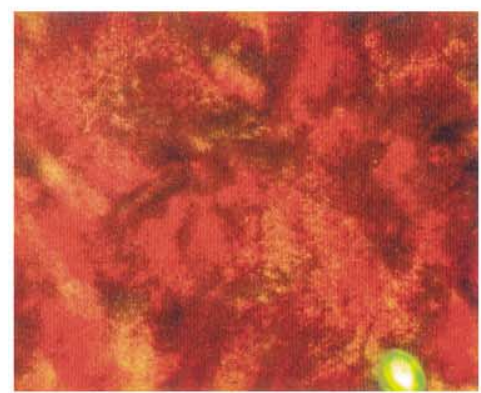

(c)

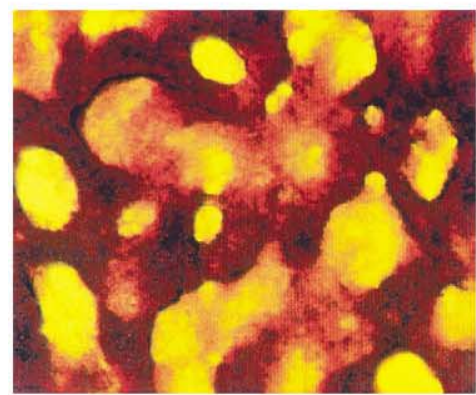

(e)

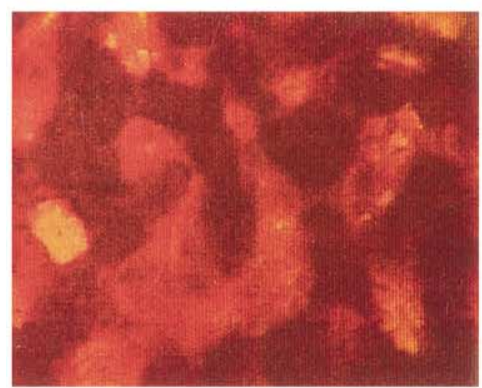

(g)

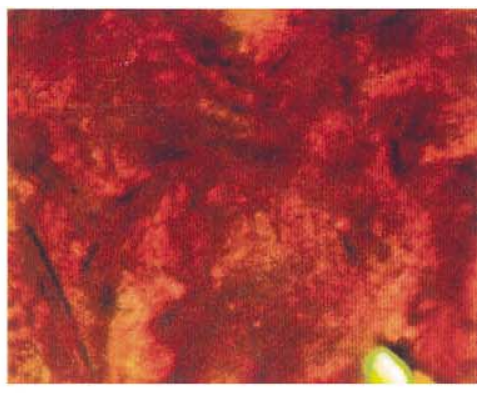

(b)

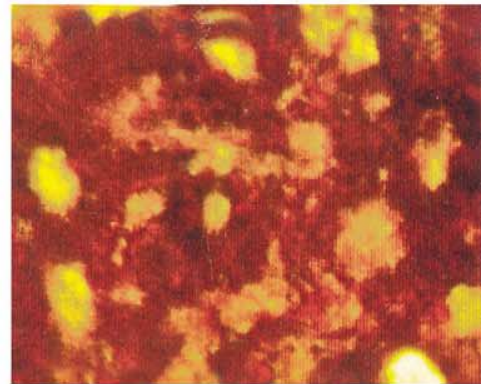

(d)

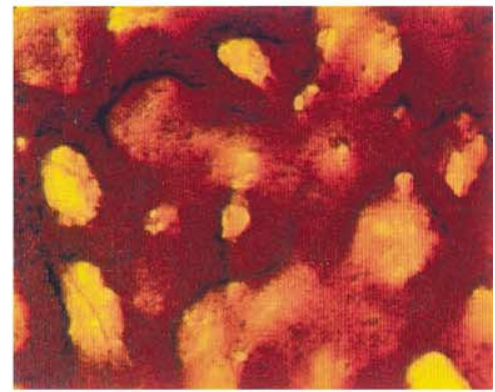

(f)

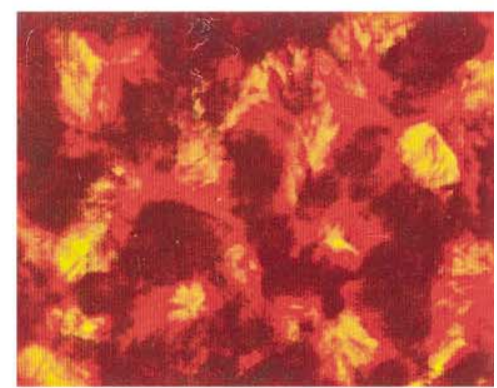

(h)

Fig. 7. Optical microscopy pictures of PTAA/PEO $30 / 70$ with 400 magnifications: (a) $27^{\circ} \mathrm{C}$ showing a shining crystalline domain of PEO-rich region and a yellow color due to the immersion of the PTAA molecules into PEO-rich region; (b) $63^{\circ} \mathrm{C}$ crystals start to melt and the shining regions gradually disappear and the picture looks more homogenous and darker; (c) $70^{\circ} \mathrm{C}$ the crystals are totally melted and the color become darker; (d) $109^{\circ} \mathrm{C}$ the intensity of light increased and some shining dots (PEO-rich phase) appear; (e) $140^{\circ} \mathrm{C}$ the contrast between the phases is enhanced when; (f) $160^{\circ} \mathrm{C}$ the phase boundaries become vague resulting from the origination of degradation of PTAA; $(\mathrm{g}) 182^{\circ} \mathrm{C}$ the degradation is enhanced and cause the disappearance of the boundaries and (h) cooled back to $40^{\circ} \mathrm{C}$, the PEO molecules were able to re-crystallize and shows the island-like crystalline domain. 
immersion of the PTAA molecules into the PEO domain. The composition of PEO in the amorphous region of the PTAA/PEO blend at 30/70 ratio is actually less than $70 \%$ due to the consumption of some PEO molecules to form the PEO-rich crystallite in the blends. At higher temperature, $63^{\circ} \mathrm{C}$ (Fig. 7(b)), crystals start to melt, which can be seen from the gradual disappearance of the shining region, and the picture looks more homogenous and darker. At this temperature, the composition of the PTAA/PEO blend in the amorphous part is possible at 30/70 ratio since all the crystallized PEO molecules melted and joined into the amorphous mixture. Therefore, the blend makes it look darker. Until the temperature raised up to $70^{\circ} \mathrm{C}$ (Fig. 6(c)), the crystals are totally melted and the color of the blend becomes darker. When the temperature was increased to $109^{\circ} \mathrm{C}$ (Fig. $7(\mathrm{~d})$ ), the intensity of light increased and some shining dots (PEO-rich phase) appeared since the phase separation happened and PEO-rich region formed the bright domains. The surfaces for the amorphous and crystalline parts of PEO show the same shining spots under a non-polarized microscopy. The contrast between the phases is enhanced when the temperature is raised to $140^{\circ} \mathrm{C}$ (Fig. 7(e)) and the late stage of phase separation occurs at this temperature. If temperature is decreased at this point, the shining spots are retained and the separated phases do not re-mix into one phase referring to an irreversible phase separation. When temperature is further elevated up to $160^{\circ} \mathrm{C}$ (Fig. 7(f)), the phase boundaries become vague resulting from the origination of degradation of PTAA which can be understood from the degraded behavior shown in Fig. 6. At $182^{\circ} \mathrm{C}$ (Fig. $7(\mathrm{~g})$ ) the degradation is enlarged and causes the disappearance of the boundaries. When the sample was cooled back to $40^{\circ} \mathrm{C}$ (Fig. 7(h)), the PEO molecules were able to re-crystallize and shows the island-like crystalline domain due to the high extent of phase separation which makes more pure PEO domains in the blend. Other compositions experienced the similar morphological changes upon heating.

The rough cloud points were defined as the temperatures when a sharp increase of the exposure time of the camera in OM, which were used to construct a LCST type PD as shown in Fig. 8. The melting points of depression line were constructed according to the data obtained from the DSC thermograms. The data above $160^{\circ} \mathrm{C}$ cannot be trusted due to the possible degradation. A miscibility window is obtained between the phase equilibrium curve and the melting point depression line.

\subsection{Conductivity measurement}

Basically the existence of the interaction does not affect the conductivity of the blends very much as seen from Table 3. However, it makes a miscible blend at room temperature possible and from which we can obtain different morphologies. In other words, according to this PD we can roughly define the miscible or immiscible window and

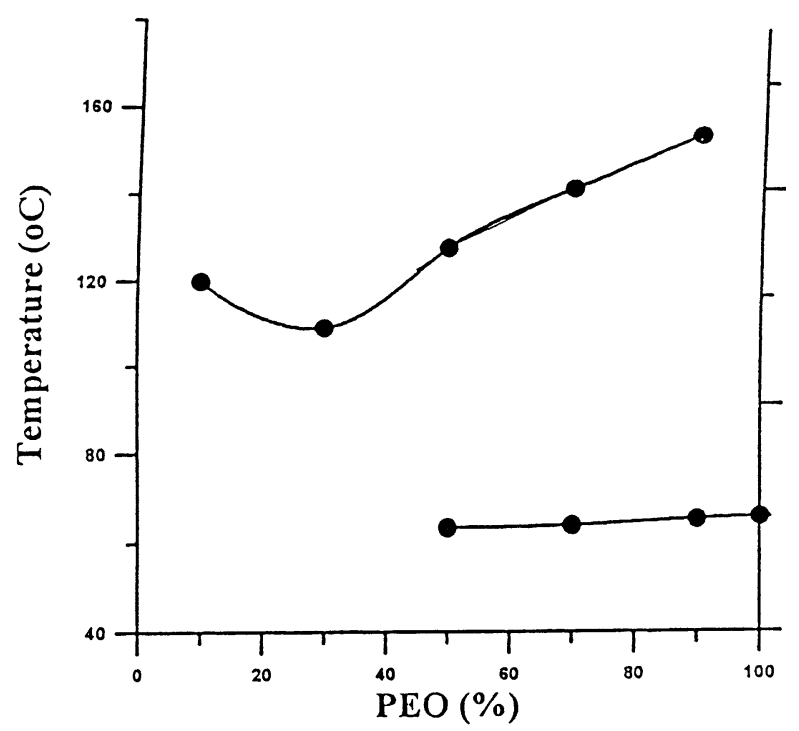

Fig. 8. Phase diagram and melting point depression line of PTAA/PEO.

Table 3

Conductivity $(\sigma)$ of heat treated PTAA/PEO blends followed by doping in $\mathrm{I}_{2}$ vapor

\begin{tabular}{ll}
\hline PTAA/PEO & $\sigma(\mathrm{S} / \mathrm{cm})$ \\
\hline $100 / 0$ & $2.12 \mathrm{E}-4$ \\
$90 / 10$ & $1.43 \mathrm{E}-5$ \\
$70 / 30$ & $4.75 \mathrm{E}-5$ \\
$50 / 50$ & $1.93 \mathrm{E}-6$ \\
\hline
\end{tabular}

control the morphologies by changing the composition and heating conditions.

The heating rate of $5^{\circ} \mathrm{C} / \mathrm{min}$ was slow enough to cause the nucleation type (island-like) of phase separation for the PEO molecules to form the non-continuous islands, which enables PTAA-rich region form the continuous and the blend is able to transport the charge through this region (Table 3). This can only be created after staying at higher temperature when phase separation happens. The conductivity (Table 3) of the blend is about one order less than that of pure PTAA due to the dilution effect of some non-conduction PEO mixed in the PTAA-rich regions. Because the PEO-rich shining spots grow at high temperature, we can create the phase separation to a continuing phase by increasing the temperature which the PEO-rich island will become larger and touch each other resulting in a narrow and pure strip of PTAA-rich phase. This would increase the conductivity of the blends. However, the degradation of PTAA might start above $160^{\circ} \mathrm{C}$, which also causes the decrease of conductivity.

\section{Conclusions}

The neutralization of acetic acid groups of PTAA by $1.5 \%$ aqueous ammonia solution resulting in the formation of the absorption at 1560 and $1370 \mathrm{~cm}^{-1}$ which are correspond 
to $-\mathrm{COO}^{-}$and $-\mathrm{NH}_{4}{ }^{+}$, respectively. The PTAA and PEO molecules are found to be able to link each other together through the $\mathrm{NH}_{4}{ }^{+}$bridge which form ionic bonding with $\mathrm{COO}^{-}$of PTAA in one end and $\mathrm{H}$-bonding with PEO in the other. This specific interaction causes a $T_{\mathrm{m}}$ depression and the decreasing heats of fusion of PEO crystals. At lower composition of PEO, it can even stop the re-crystallization of PEO when cooled down from the molten state by the purging nitrogen gas in the DSC cell.

The crystalline lattice of the PEO and PTAA crystals did not present after blending since only $5 \%$ of PTAA backbone unit are able to create the interaction with PEO. TGA study demonstrates the possible degradation of ammonia-watercast PTAA, PEO, and their blends. A 50/50 blend has a weight loss starting at a higher temperature than pure PTAA due to the exsistence of $50 \%$ PEO.

A PD can be constructed by the melting points obtained from DSC thermograms and the cloud points defined as the temperature when a sharp increase of the exposure time of the camera in optical microscopy. This PD is proved to be a LCST type with $T_{\mathrm{m}}$ depression line below the equilibrium line. The conductivity of blends can be measured after heating due to the formation of the continuous $\mathrm{I}_{2}$ doped PTAA phase after phase separation. They are one order less than the pure $I_{2}$ doped PTAA. However, the existence of the specific interaction between the PTAA and PEO does not influence the conductivity of blends very much.

\section{Acknowledgements}

The authors acknowledge with gratitude financial support from the National Science Council, Taiwan, ROC through Grant no. NSC 85-2216-E002-004 and NSC 88-2216-E224002 .

\section{References}

[1] M. Takayanagi, T.J. Katayose, Polym. Sci. Polym. Chem. 21 (1983) 31.

[2] R.L. Elsembauer, G.G. Miller, Y.P. Khanna, E. McCarthy, R.H. Banghman, Electrochem. Soc. Ext. Abstr. 85 (1985) 1.

[3] K.S. Ho, K. Levon, W.Y. Zheng, J. Laakso, Synth. Met. 57 (1993) 3591.

[4] S.A. Chen, J.M. Ni, Macromolecules 25 (1992) 6081.

[5] S. Hotta, S.D.D.V. Rughooputh, A.J. Heeger, F. Wudl, Macromolecules 20 (1987) 212.

[6] S.M. Aharoni, Macromolecules 14 (1981) 222.

[7] K.Y. Jen, G.G. Miller, R.L. Elsenbaumer, J. Chem. Soc. Chem. Commun. 1346 (1986).

[8] R. Sugimoto, S. Takeda, H.B. Gu, K. Yoshino, Chem. Express 1 (1986) 635.

[9] M. Sato, S. Tanada, K.J. Kaeriyama, J. Chem. Soc., Chem. Commun. (1986) 873.

[10] A.J. Heeger, Synth. Met. 55 (1993) 3471.

[11] Y. Cao, G.M. Treacy, P. Smith, A.J. Heeger, Synth. Met. 57 (1993) 3526.

[12] Y. Cao, A.J. Heeger, Synth. Met. 52 (1992) 193.

[13] Y. Cao, P. Smith, A.J. Heeger, Synth. Met. 57 (1993) 3514.

[14] J. Laakso, J.E. Osterholm, P. Nyholm, Synth. Met. 28 (1989) C467.

[15] S. Hotta, S.D.D.V. Rughooputh, A.J. Heeger, Synth. Met. 22 (1987) 79.

[16] M. Aldissi, A.R. Bishop, Polymer 26 (1985) 622.

[17] A. Royappa, M.F. Rubner, Langmuir 8 (1992) 3168.

[18] M. Takayanagi, T. Katayaose, J. Appl. Polym. Sci. 29 (1984) 141.

[19] E. Martuscelli, C. Silvestre, C. Gismodi, Makromol. Chem. 186 (1985) 2161.

[20] E. Martuscelli, C. Silvestre, M. Addonizio, L. Amelino, Makromol. Chem. 187 (1986) 1577.

[21] N.B. Colthup, L.H. Daly, S.E. Wilberley, Introduction to Infrared and Raman Spectrum, 3rd Edition, 1990.

[22] O.T. Ikkala, J. Laakso, K. Vakiparta, E. Virtanen, H. Ruohonen, H. Jarvinen, T. Taka, P. Passiniemi, Synth. Met. 69 (1995) 97.

[23] A. Andreatta, P. Smith, Synth. Met. 55 (1993) 1017.

[24] P. Passiniemi, K. Vakiparta, Synth. Met. 69 (1995) 237.

[25] Y. Cao, P. Smith, C. Yang, Synth. Met. 69 (1995) 191. 